\title{
The Effect of 8-Week Core Training on Balance, Agility and Explosive Force Performance
}

\author{
Nurten Dinç, ${ }^{1, *}$ Esin Ergin ${ }^{2}$ \\ ${ }^{1}$ Faculty of Sports Sciences, Manisa Celal Bayar University, Turkey \\ ${ }^{2}$ Faculty of Sports Sciences, Adnan Menderes University, Turkey
}

Copyright $\bigcirc 2019$ by authors, all rights reserved. Authors agree that this article remains permanently open access under the terms of the Creative Commons Attribution License 4.0 International License

\begin{abstract}
The aim of this study was to investigate the effects of core strength training on balance, explosive force and agility. 28 athletes volunteered in the study. The athletes were separated into two groups: the experimental group $(n=15)$ with the average of age and weight of $19.5 \pm$ 1.2 years and $64 \pm 8.9 \mathrm{~kg}$, respectively and the control group $(n=13)$ with average age and weight of $19.4 \pm 1.5$ years and $67.4 \pm 10.3 \mathrm{~kg}$ respectively. During the intervention, both groups continued their normal training sessions for 8 weeks. The experimental group performed thirteen core movements 3 times a week for 8 weeks, while control group did not. The experimental group performed each movement with 20 repetitions of 3 sets and a 1 minute rest between sets. Pre and post-intervention, standing long jump, Illinois and double right/left foot balance tests were used to determine the explosive force, agility and balance performance, respectively. Wilcoxon Signed Ranks test was used for the analysis of the difference between pre-test and post-test groups and Mann Whitney U test was used for the comparison of the two groups. In order to make statistical analysis of the study, the significance level was accepted as $\mathrm{p}<0.05$. After the 8 week intervention, both groups' participants showed significant improvement in the explosive force and agility performance; whereas no significant difference was found in the double right/left foot balance test results. When the difference between the groups was examined, the post test results showed a significant difference in long jump and agility tests. The post test results of the experimental group were found to be higher than the control group. The 8-week core strength training intervention showed no effect on athletes' balance but a positive effect on long jump and agility were observed.
\end{abstract}

Keywords Core training, Agility, Balance

\section{Introduction}

Muscle strength, flexibility, endurance, coordination, balance and movement efficiency are essential components and integral parts of performance to achieve the functional movement in skill related to sports [1, 2]. In order to achieve optimal performance in amateur and professional sports, it is important that the body has sufficient strength and durability. Core stability and balance are critically important almost for all kinds of sports and activities. Although many sports branches require a good balance, power generation or body symmetry, they all depend on core stability in three motion planes [3].

Core training focuses on strength and power development of local and global muscles which work together to stabilize the spine. Global (outer) muscles include rectus abdominis, obliques, latissimus and erecter spinal muscles while local (deeper) muscle groups include transverse abdominis, multifidus, and pelvic floor muscles [4]. Running is a motion that puts more focus on the lower extremity, insufficient strength of the muscles stabilizing the pelvis and trunk increase of uncontrollability the body center of gravity and are associated with injuries [5]. According to another study, it is believed that the weakness or lack of coordination in core muscles disturbs the transfer of energy, in addition, strain and overuse leads decreased effectiveness of movements which also may lead to injuries $[6,7]$. It is believed among the experts that the core strength training is one of the most important components in the field of power and conditioning in order to improve athletic performance and to prevent the risk of injury [8] and it is often used in the strength, health, fitness and rehabilitation industries [9]. Core training is stated as not only playing a key role in reducing back pain and rehabilitation of injuries [10]but also avoiding and reduction of injuries in lower extremities as well [11].

Recently, various training methods have been developed for the stabilization of the core region. These exercises are considered to be effective methods to strengthen muscles, to increase flexibility and balance performance for not only professionals but also for sedentary people for all ages and gender [12]. On the other hand, these workouts are widely used in training planning to enhance performance. Core 
muscles are important components in maximizing balance and athletic performance in lower extremity movements [11] while stabilizing the spine and trunk during upper extremity movements such as jumping, running and throwing [13]. It is theorized that a strong core region will ease the transfer of force from the lower body to the upper body while making the energy consumption in the body more efficient [7].

When the current literature is examined; Manchado et al. (2017) stated that the core training applied to the male handball players for 10 weeks caused improvement in throwing speed [14] while Watson et al. (2017), after a core stabilizing 9-week program implementation, observed improvements in static and dynamic balance and muscle performance test scores in the pivot-turning ability of dancers [15]. Afyon et al. (2017) stated that the core training increased the speed and agility performance of football players [16] and Taskin (2016) examined improved speed, acceleration, vertical jump and long jump performance of female football players after core training interventions [19]. A 6-week core training intervention in football players showed increased speed performance [20] while Iocano et al. (2014) showed that 4-week core training improved the static and dynamic balance performance of footballers [21]. On the other hand studies by Sever and Zorba (2018) and Prieske et al. (2016) reported no effect on agility skills after a core training intervention in football players [17, 18]. In addition, Sato and Mokha (2009) determined in a study of $5000 \mathrm{~m}$ runners that 6-week core strength training did not have a significant effect on balance ability [8].

Physiologically, it is believed that core strength stability trainings provide increase in maximal strength and effective use of shoulders, arms, and legs muscles [22]. Because of having more pressure on lower extremity muscles of runners, it is important train core muscles, specifically the pelvis and trunk. Studies on core stability of runners and core training are limited while literature on different branches are found. Therefore, the aim of this study is to determine "the effects of 8-week core training on balance, agility and explosive force performance.

\section{Materials and Methods}

\section{Participation}

28 runners participating actively in the races who were over the age of 18 volunteered in the study. Participants were randomly assigned to the experimental group $(n=15)$ and the control group (13 people). The experimental group had average age and weight of $19.5 \pm 1.2$ years and $64 \pm 8.9$ $\mathrm{kg}$, respectively and the control group was $19.4 \pm 1.5$ years and $67.4 \pm 10.3 \mathrm{~kg}$. All participants were given informed consent form. Ethics committee approval of the study was obtained from the ethics committee of Health Sciences
Ethics Committee of Manisa Celal Bayar University. The health reports were obtained from the participants before the study.

\section{Test Protocol}

During the intervention, both groups continued their normal training sessions for 8 weeks. The experimental group performed thirteen core movements 3 times a week for 8 weeks, while control group did not. The experimental group performed each movement with 20 repetitions of 3 sets and a 1 minute rest between sets. Pre and post-intervention, standing long jump, Illinois and double right/left foot balance tests were used to determine the explosive force, agility and balance performance, respectively. The training program of the experimental group is given in table 1 .

Table 1. The training program of the experimental group

\begin{tabular}{|l|c|c|c|}
\hline & times & repetation & Rest (min) \\
\hline Bosu planks & 3 & 20 & 1 \\
\hline Bosu side plank & 3 & 20 & 1 \\
\hline Crunch Cycle Exercise & 3 & 20 & 1 \\
\hline Bosu Reverse Plank & 3 & 20 & 1 \\
\hline Bosu crunch & 3 & 20 & 1 \\
\hline Cross crunch & 3 & 20 & 1 \\
\hline Back extantion & 3 & 20 & 1 \\
\hline V up exercise & 3 & 20 & 1 \\
\hline Bosu leg raise & 3 & 20 & 1 \\
\hline Bosu reverse extantion & 3 & 20 & 1 \\
\hline Rotary stabilty & 3 & 20 & 1 \\
\hline Bosu crunch cycle & 3 & 20 & 1 \\
\hline Bosu back extantion & 3 & 20 & 1 \\
\hline
\end{tabular}

\section{Illinois Test}

The test track had the width of $5 \mathrm{~m}$ and length of $10 \mathrm{~m}$ and included three cones in a straight line at a distance of $3.3 \mathrm{~m}$ from each other. The test was held in an indoor athletics hall with a synthetic ground. The test consisted of $40 \mathrm{~m}$ straight runs with $180^{\circ}$ turns in every $10 \mathrm{~m}$ and slalom runs between cones in every $20 \mathrm{~m}$ (Fig. 1) [23].

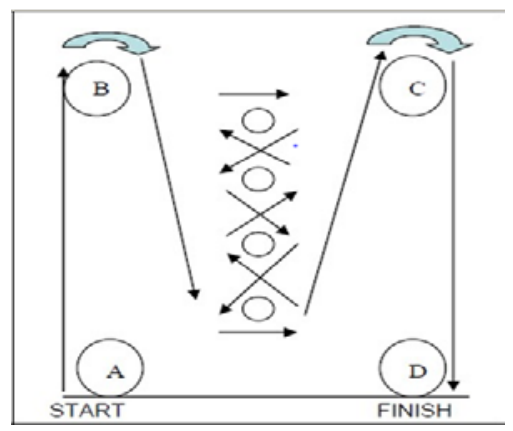

Figure1. Illinois Test 


\section{Standing Long Jump}

From the standing position, the double leg front jumps are measured in centimeters between the point of the jump and the end of the long jump. The test was repeated twice and the best result was recorded.

\section{Balance Test}

The balance data were taken with the Core Balance Portable Balance device. Balance data were obtained by 3 different measurements: double feet, right foot and left foot.

\section{Statistical Analysis}

The study started with 28 participants but 3 quit. The results of 25 participants were used in the statistical analysis. The statistical data of the study were analyzed with SPSS 22 software. Wilcoxon Signed Ranks test was used for the analysis of the difference between the pre-tests and post-tests of the groups and Mann Whitney U test was used for the comparison of the two groups. The significance level was accepted as $p<0.05$.

\section{Results}

Wilcoxon Signed Ranks results which are used to determine the statistical difference between the pre and post test results of right-left foot, double foot balance, agility and explosive force of participants are given in Table 2.

While there was a statistically significant improvement in the performance of explosive force and agility in both the experimental and the control groups in the pre- and post-test. There was no significant difference in the results of double / right / left foot balance test.

The results of the Mann Whitney $U$ test which is used to demonstrate the difference between the groups are given in Table 3.

Table 2. Pre and post training test values of experimental and control group

\begin{tabular}{|c|c|c|c|c|c|c|}
\hline & \multicolumn{3}{|c|}{ Experimental group (n=15) } & \multicolumn{3}{c|}{ Control group (n=10) } \\
\hline & Pre & Post & $\boldsymbol{p}$ & Pre & Post & $\boldsymbol{p}$ \\
\hline Standing long jump & $2.33 \pm 0.33$ & $2.40 \pm 0.28$ & $0.01 *$ & $2.04 \pm 0.37$ & $2.11 \pm 0.36$ & $0.00^{*}$ \\
\hline Illinois Test & $16.54 \pm 0.87$ & $15.66 \pm 0.78$ & $0.00 *$ & $16.97 \pm 1.17$ & $16.48 \pm 0.90$ & $0.00^{*}$ \\
\hline Both Legs & $705.93 \pm 145.96$ & $784.00 \pm 164.28$ & 0.17 & $705.70 \pm 158.52$ & $861.60 \pm 162.11$ & 0.09 \\
\hline Right Leg & $969.0 \pm 310.35$ & $1102.20 \pm 198.84$ & 0.17 & $1127.60 \pm 480.18$ & $1287.50 \pm 516.37$ & 0.28 \\
\hline Left Leg & $928.13 \pm 227.73$ & $1054.73 \pm 319.40$ & 0.14 & $1143.20 \pm 359.42$ & $1031.70 \pm 426.14$ & 0.44 \\
\hline
\end{tabular}

Wilcoxon Signed Ranks test results between pre- and post-values in a group. ${ }^{*} p<0.05$

Table 3. The difference between the experimental group and control group.

\begin{tabular}{|c|c|c|c|c|c|c|}
\hline \multicolumn{2}{|c|}{ Variables } & $\mathbf{N}$ & Mean Rank & Sum of Ranks & $\mathbf{U}$ & $\mathbf{P}$ \\
\hline \multirow{2}{*}{$\begin{array}{c}\text { Pre-test } \\
\text { Standing long jump }\end{array}$} & Control & 10 & 9,55 & 95,50 & \multirow{2}{*}{40,500} & \multirow{2}{*}{0,055} \\
\hline & Experimental & 15 & 15,30 & 229,50 & & \\
\hline \multirow{2}{*}{$\begin{array}{c}\text { Post-test } \\
\text { Standing long jump }\end{array}$} & Control & 10 & 9,30 & 93,00 & \multirow{2}{*}{38,000} & \multirow{2}{*}{$0,04 *$} \\
\hline & Experimental & 15 & 15,47 & 232,00 & & \\
\hline \multirow{2}{*}{$\begin{array}{l}\text { Pre-test } \\
\text { Illinois }\end{array}$} & Control & 10 & 15,35 & 153,50 & \multirow{2}{*}{51,500} & \multirow{2}{*}{0,192} \\
\hline & Experimental & 15 & 11,43 & 171,50 & & \\
\hline \multirow{2}{*}{$\begin{array}{l}\text { Post-test } \\
\text { Illinois }\end{array}$} & Control & 10 & 16,65 & 166,50 & \multirow{2}{*}{38,500} & \multirow{2}{*}{$0,043^{*}$} \\
\hline & Experimental & 15 & 10,57 & 158,50 & & \\
\hline \multirow{2}{*}{$\begin{array}{l}\text { Pre-test } \\
\text { Both legs }\end{array}$} & Control & 10 & 12,65 & 126,50 & \multirow{2}{*}{71,500} & \multirow{2}{*}{0,846} \\
\hline & Experimental & 15 & 13,23 & 198,50 & & \\
\hline \multirow{2}{*}{$\begin{array}{l}\text { Post-test } \\
\text { Both legs }\end{array}$} & Control & 10 & 15,10 & 151,00 & \multirow{2}{*}{54,000} & \multirow{2}{*}{0,244} \\
\hline & Experimental & 15 & 11,60 & 174,00 & & \\
\hline \multirow{2}{*}{$\begin{array}{l}\text { Pre-test } \\
\text { Right leg }\end{array}$} & Control & 10 & 14,30 & 143,00 & \multirow{2}{*}{62,000} & \multirow{2}{*}{0,471} \\
\hline & Experimental & 15 & 12,13 & 182,00 & & \\
\hline \multirow{2}{*}{$\begin{array}{l}\text { Post-test } \\
\text { Right leg }\end{array}$} & Control & 10 & 13,80 & 138,00 & \multirow{2}{*}{67,000} & \multirow{2}{*}{0,657} \\
\hline & Experimental & 15 & 12,47 & 187,00 & & \\
\hline \multirow{2}{*}{$\begin{array}{l}\text { Pre-test } \\
\text { Left leg }\end{array}$} & Control & 10 & 13,50 & 135,00 & \multirow{2}{*}{70,000} & \multirow{2}{*}{0,782} \\
\hline & Experimental & 15 & 12,67 & 190,00 & & \\
\hline \multirow{2}{*}{$\begin{array}{l}\text { Post-test } \\
\text { Left leg }\end{array}$} & Control & 10 & 14,30 & 143,00 & \multirow{2}{*}{62,000} & \multirow{2}{*}{0,471} \\
\hline & Experimental & 15 & 12,13 & 182,00 & & \\
\hline
\end{tabular}

Mann-Whitney U-test results between pre and post values in both groups 
When the differences between groups were examined, significant difference was found in long jump and agility scores in the post test results. It is determined that the post test results of the experimental group are higher than the results of the control group. The final test results of the experimental group were found to be higher than the control group.

\section{Discussion}

In this study, the effects of 8-week core training on balance, agility, and explosive force performance were investigated. When the results were examined, a statistically significant improvement was observed in both the experimental and the control groups in terms of explosive force and agility performance $(p<0.05)$ while there was no significant difference in double, right/left foot balance test results ( $>0.05$ ). In addition, when the difference between the groups was compared, it was found that there was a statistically significant difference in the long jump and agility tests after 8 weeks in the control group and the experimental group ( $\mathrm{p}<0.05)$. The final test results of the experimental group were found to be higher than the control group.

Studies on core stability and core training of runners are limited while literature on different branches and core training are found. Sandrey and Mitzek (2013) found significant increases in balance ability with the 6-week Core training in college athletes [24]. However, Sato and Mokha (2009) reported that the 6-week Core strength training did not have a significant effect on balance ability of $500 \mathrm{~m}$ runners [8]. Sato (2009)'s study supports the balance test findings of this study. It is thought that the reason why core training has no effect on balance in runners is due to the type I muscle fibrils with aerobic properties in long distance runners. It is known that the average of the force output is slower in athletes with type I muscle fibers than the athletes with type II muscle fibers. When we look at the studies in different branches, Watson et al. (2017) found some significant increases on dance and balance performance of the core training applied on dancers 3 days a week for 9 weeks [15]. Kahle et al. (2009) stated that 6-week core training can improve dynamic postural control in the treatment and rehabilitation process of injuries [25]. Iacono et al. (2014) reported that the 4-week 5 days a week core balance training with 11 exercises significantly improved static and dynamic balance on young football players [21]; similarly, Granacher et al. (2014) stated that there are significant increases on balance values of both groups (stable and unstable surfaces) when two different 6-week Core force programs applied on 23 football players were compared. [26]. Moreover, it is thought that balance skills of football players are more developed than runners due to the fact that in training and competitions as football players are exposed to external influences such as shoulder-to-shoulder struggles and falls after jumps.

Agility is defined as rapid movement of the body with a change in speed or direction in response to a stimulus [27]. This ability includes many factors such as leg strength, running technique and in order to move quickly, it also requires muscle strength [28]. When the literature is examined, studies on the core training of various branches are observed. Afyon et al. (2017) stated that there are significant improvements in agility and speed skills when an 8-weeks four days a week core training program is implemented to the football players' regular training program [16]. Although this study showed that core training had a statistically significant effect on agility and explosive force Sever and Zorba (2018) and Prieske et al. (2016) reported that core training has no effect on agility skills as a result of their work on football players $[17,18]$. In the study of Ozmen and Aydogmus (2016) on adolescent badminton players with a 6-week core training intervention, in the pre-test and post-test scores of the experimental group significant differences were observed while between the groups, there were none. [11]. Schilling et al. (2013) observed significant increases in 3 different core endurance tests (back extensor durability, flexor endurance and side muscle strength) in a 6-week core force and endurance training intervention applied 2 times a week on non-active individuals; however no change in sprint, agility, and vertical jump is reported [29]. The reason why the agility results of the study mentioned above differs from ours can be related to the age and activeness in sports. Agility performance reduction is inevitable if there is a strength difference between the muscles or muscle groups or a defect in the angles of biomechanical movement working during agility. These factors mentioned above should be carefully examined in order to achieve accurate results.

Performance improvement in agility requires various training methods working together and does not rely only on the core training. When the literature reviewed, there are very few researches that show the relationship between agility and core strength training in athletics. However, agility results of the experimental group in our study were higher than the control group, suggesting a relationship between core strength and agility.

\section{Conclusions}

As a result, it can be seen that the core training in the athletics branch has a positive effect on the ability of explosive force and agility, but it does not have a positive effect on balance ability. Performance improvement in agility and explosive force requires various training methods working together and does not rely only on the core training. When the literature reviewed, there are very few researches that shows the relationship between agility, explosive force, balance and core training in athletics. So 
our suggestion is to do more studies with different branches and demographic variations in core training methods.

\section{REFERENCES}

[1] Cook, G. Baseline sports-fitness testing. In: High Performance Sports Conditioning. B. Foran, ed. Champaign, IL: Human Kinetics Inc, 2001. pp. 19-47.

[2] Okada, T., Huxel K.C., Nesser W. (2011). Relationship between core stability, functional movement and performance. The journal of Strength and conditioning association, 25(1), 252-261.

[3] Hibbs, A.E., Thompson, K.G., French, D., Wrigley, A., Spears, L. (2008). Optimizing performance by improving core stability and core strength. Sports Medicine, 38(12), 995-008.

[4] Sekendiz, B., Cug, M., Korkusuz, F. (2010). Effects of swiss-ball core strength training on strength, endurance, flexibility, and balance in sedentary women. Journal of Strength and Conditioning Research, 24(11), 3032-3040.

[5] Koblbauer, I.F., van Schooten, K.S., Verhagen, E.A., van Dieën, J.H. (2014). Kinematic changes during running-induced fatigue and relations with core endurance in novice runners. Journal of Science and Medicine in Sport, 17(4), 419-424.

[6] Fredericson, M., Moore, T. (2005). Muscular balance, core stability and injury prevention for middle- and long-distance runners. Physical Medicine and Rehabilitation Clinics of North America, 16(3), 669-689.

[7] Nesser, T.W., \& Lee, W.L. (2009). The relationship between core strength and performance in division I female soccer players. Journal of Exercise Physiology Online, 12(2), 21-28.

[8] Sato, K., Mokha, M., (2009). Does core strength training influence running kinetics, lower-extremity stability, and 5000-m performance in runners? The Journal of Strength and Conditioning Research, 23(1), 133-140.

[9] McGill, S.M. (2001). Low back stability: from formal description to issues for performance and rehabilitation. Exercise and sport sciences reviews, 29(1), 26-31.

[10] McGill, S.M., Grenier, S., Kavcic, N., Cholewicki, J. (2003). Coordination of muscle activity to assure stability of the lumbar spine. Journal of Electromyography and Kinesiology, 13(4), 353-359.

[11] Ozmen, T., Aydogmus, M. (2016). Effect of core strength training on dynamic balance and agility in adolescent badminton players. Journal of Bodyworkand Movement Therapies, 20(3), 565-570.

[12] Park, J., Hyun, G., Jee, Y. (2016). Effects of Pilates core stability exercises on the balance abilities of archers. Journal of Exercise Rehabilitation, 12(6), 553-558.

[13] Kibler, W., Press, J., Sciascia, A. (2006). The role of core stability in athletic function. Sports Medicine, 36(3),
189-198.

[14] Manchado, C., García-Ruiz, J., Cortell-Tormo, J.M., and Tortosa-Martínez, J. (2017). Effect of core training on male handball players' throwing velocity. Journal of Human Kinetics, 56, 177-185.

[15] Watson, T., Graning, J., McPherson, S., Carter, E., Edwards, J., Melcher, I., Burgess, T. (2017). Dance, balance and core muscle performance measures are improved following a 9-week core stabilization training program among competitive collegiate dancers. The International Journal of Sports Physical Therapy, 12(1), 25-41.

[16] Afyon, Y., Mulazimoglu, O., Boyaci, A. (2017). The effects of core trainings on speed and agility skills of soccer players. International Journal of Sports Science, 7(6), 239-244.

[17] Sever, O., \& Zorba, E. (2018). Comparison of static and dynamic core exercises' effects on speed and agility performance in soccer players. Isokinetics and Exercise Science, 26(1), 29-36.

[18] Prieske, O., Muehlbauer, T., Borde, R., Gube, M., Bruhn, S., Behm, D. G., Granacher, U. (2016). Neuromuscular and athletic performance following core strength training in elite youth soccer: Role of instability. Scandinavian journal of medicine \& science in sports, 26(1), 48-56.

[19] Taskin, C. (2016). Effect of core training program on physical functional performance in female soccer players, International Education Studies, 9(5), 115-123.

[20] Mendes, B. (2016). The effects of core training applied to footballers on anaerobic power, speed and agility performance. Anthropologist, 23(3), 361-366.

[21] Iacono, A., Martone, D., Alfieri, A., Ayalon, M., Buono, P. (2014). Core stability training program (CSTP) effects on static and dynamic balance abilities. Gazzetta Medica İtaliana Archivio per le Scienze Mediche, 173(4), 197-206.

[22] Lehman, G.J. (2006). Resistance training for performance and injury prevention in golf. The Journal of the Canadian Chiropractic Association, 50(1), 27-42.

[23] Hazır, T., Mahir, Ö.F., Açıkada, C. (2010). Genç futbolcularda çeviklik ile vücut kompozisyonu ve anaerobik güç arasındaki ilişki. Spor Bilimleri Dergisi, 21(4), 146-153.

[24] Sandrey, M.A., \& Mitzel, J.G. (2013). Improvement in dynamic balance and core endurance after a 6-week core-stability-training program in high school track and field athletes. Journal of sport rehabilitation, 22(4), 264-271.

[25] Kahle, N., Gribble, P. (2009). Core stability training in dynamic balance testing among young, healthy adults. Athl Train Sports Health Care, 1(2), 65-73.

[26] Granacher, U., Schellbach, J., Klein, K., Prieske, O., Baeyens, J. P., Muehlbauer, T. (2014). Effects of core strength training using stable versus unstable surfaces on physical fitness in adolescents: a randomized controlled trial. BMC Sports Science, Medicine and Rehabilitation, 15; 6(1), 40.

[27] Sheppard, J.M., \& Young, W.B. (2006). Agility literature review: Classifications, training and testing. Journal of sports sciences, 24(9), 919-932. 
[28] Young, W.B., Dawson, B., \& Henry, G.J. (2015). Agility and change-of-direction speed are independent skills: Implications for training for agility in invasion sports. International Journal of Sports Science \& Coaching, 10(1), 159-169.

[29] Schilling, J.R, Murphy, J.C., Bonney, J.R., \& Thich, J.L. (2013). Effect of core strength and endurance training on performance in college students: randomized pilot study. Journal of bodywork and movement therapies, 17(3), 278-290. 